\title{
Early hospital discharge of infants born to group B streptococci-positive mothers: a decision analysis
}

\author{
MB Berger, ${ }^{a}$ X Xu, ${ }^{a}$ JA Williams, ${ }^{\text {a,b }}$ CJM Van de Ven, ${ }^{a}$ EL Mozurkewich ${ }^{a}$ \\ ${ }^{a}$ Department of Obstetrics and Gynecology, University of Michigan Health System and ${ }^{\mathrm{b}}$ Department of Obstetrics and Gynecology, \\ St Joseph Mercy Health System, Ann Arbor, MI, USA \\ Correspondence: Dr MB Berger, Department of Obstetrics and Gynecology, University of Michigan Health System, L4000 Women's Hospital, \\ 1500 East Medical Center Drive, Room, Ann Arbor, MI 48109-5276, USA. Email mitcberg@umich.edu
}

Accepted 12 November 2011. Published Online 18 January 2012.

Objective To compare the cost-effectiveness of an additional 24-hour inpatient observation for asymptomatic term neonates born to group B streptococcus (GBS) -colonised mothers with adequate intrapartum antibiotic prophylaxis (IAP) after an initial 24-hour in-hospital observation.

Design Cost-effectiveness analysis from a societal perspective.

Setting United States.

Population Asymptomatic term neonates born to GBS-colonised mothers with IAP after an initial 24-hour in-hospital observation.

Methods Monte Carlo simulation for a decision tree model incorporating the following chance events: development of GBS sepsis during the second 24 hours of life, development of GBS sepsis between 48 hours and 7 days of life, prompt versus delayed treatment for sepsis, neonatal mortality and long-term health sequelae.

Main outcome measures Expected cost and quality-adjusted life years (QALYs), Incremental cost-effectiveness ratio (ICER).
Results Delayed, versus early, hospital discharge results in similar mean expected QALYs, but substantially higher expected cost. The mean difference in QALY is 0.00016 (95\% CI $0.00005-$ 0.00040 ), whereas the mean difference in cost is $\$ 1170.96$ (95\% CI $\$ 750.13-1584.32)$. The ICER is estimated to be $\$ 9,771,520.87$ per QALY (95\% CI \$2,573,139.89-24,407,017.82). The proportion of early-onset GBS that develops during the second 24 hours of life, the cost of 24 hours of inpatient observation, and the probability of long-term sequelae following prompt versus delayed treatment play important roles in determining the cost-effectiveness of delayed hospital discharge.

Conclusion Cost-effectiveness analysis suggests that with adequate IAP, discharging asymptomatic term neonates to home after 24 hours is the preferred approach compared with 48 hours inpatient observation.

Keywords Healthcare costs, patient discharge, postpartum period, sepsis, Streptococcus agalactiae.

Please cite this paper as: Berger M, Xu X, Williams J, Van de Ven C, Mozurkewich E. Early hospital discharge of infants born to group B streptococcipositive mothers: a decision analysis. BJOG 2012;119:439-448.

\section{Introduction}

Sepsis caused by Streptococcus agalactiae, commonly referred to as Group B Streptococci (GBS), has historically been one of the leading causes of neonatal morbidity and mortality in the USA. ${ }^{1}$ Neonatal GBS sepsis occurring before the 7th day of life is referred to as early-onset GBS (EOGBS) sepsis; ${ }^{2}$ in the past, this accounted for the majority of cases. Although improvements in newborn care have led to better outcomes for neonates that develop EOGBS sepsis, the disease remains associated with short-term and long-term morbidities and mortality, including asymptom- atic bacteraemia, pneumonia, meningitis, prolonged hospitalisation, need for ventilatory support, hearing and vision impairment, and mental retardation. ${ }^{3,4}$ The Centers for Disease Control and Prevention (CDC), the American College of Obstetricians and Gynecologists, and the American Academy of Pediatrics (AAP) therefore set a goal to identify means to prevent the development of GBS sepsis. ${ }^{1}$

As research in the latter half of the twentieth century revealed that intrapartum antibiotic prophylaxis (IAP) provided to mothers in labour could prevent the development of EOGBS sepsis in the newborn, ${ }^{5}$ these same three organisations released guidelines in 1996, subsequently revised in 
2002, and recently updated in 2010, outlining screening and treatment recommendations designed to reduce the incidence of EOGBS sepsis. The CDC now recommends screening all pregnant women for GBS colonisation between 35 and 37 weeks of gestation, and providing IAP treatment for all colonised women or women whose colonisation status is unknown but who have identified risk factors. ${ }^{6}$ Implementation of these policies has been remarkably effective, reducing the incidence of EOGBS sepsis from 1.5 to 2 cases per 1000 live births to approximately 0.3 cases per 1000 live births. ${ }^{6-8}$

Despite the success of IAP, there continues to be uncertainty over the length of time that neonates born to women known to be colonised by GBS should be observed after birth. The CDC and AAP both recommend that neonatal observation be continued for 48 hours. ${ }^{6,7,9}$ However, they also concede that neonates that appear healthy and that are born to women appropriately treated with IAP (defined as administration of antibiotics $\geq 4$ hours before delivery of the infant ${ }^{6}$ ) may be discharged after 24 hours if they can be effectively observed at home. ${ }^{6,7,10}$ At many institutions, however, neonates born to GBS-colonised women are observed for longer than 24 hours, regardless of whether adequate IAP was provided. ${ }^{11}$ This necessitates an extra night's stay for the neonate (and typically the mother as well), incurring higher costs, delayed return to the comforts of home, and increased risk of nosocomial infections.

As approximately $10-30 \%$ of all pregnant women in the USA have been shown to be colonised with GBS, ${ }^{7}$ many mothers and infants (both in the USA and in other countries that have adopted the screening approach advocated by the CDC) are currently experiencing delayed hospital discharge under the standard protocols. Given the importance of cost considerations in national and international health policy making, we undertook a cost-effectiveness analysis of delayed hospital discharge (defined as discharge after an additional 24 hours of in-hospital observation) for term, asymptomatic neonates who are born to women colonised with GBS and treated with adequate IAP.

\section{Methods}

\section{Decision tree model}

Patients in this analysis were defined as term infants who were asymptomatic at 24 hours of life but were born via vaginal delivery to women with known GBS colonisation who received adequate IAP. We constructed a decision tree model to compare two discharge approaches: (i) discharge at 24 hours and (ii) discharge at 48 hours, i.e. an additional 24-hour inpatient observation period before discharge. The model is illustrated in Figure 1, which starts at 24 hours after birth with an asymptomatic newborn. The decision node represents the two discharge approaches, and the branches following each discharge approach reflect the subsequent health events. These health events include development of GBS sepsis during the second 24 hours after birth, development of GBS sepsis 48 hours after birth but within 7 days of birth, delayed or prompt treatment for EOGBS sepsis, and resultant health outcomes (death, live infant with long-term sequelae, or live infant with no long-term sequelae). For each of these health events, the model considers its probability of happening and the associated costs and health-related quality of life. The timeframe of our analysis starts from the second 24 hours of life throughout the lifetime of the newborn. Hence the model allows us to estimate the expected outcomes of each discharge approach and compare them.

\section{Data sources}

Estimates of all input parameters for the decision tree model, including estimates of the probability, cost and utility associated with each health state, were obtained from a comprehensive literature review. In developing parameter estimates related to the probabilities of health events, two authors (MBB and ELM) searched the English-language literature from 1 January 1993 to 5 November 2009 using the databases Medline, Pubmed and EMbase and search terms 'group B streptococcus' or 'agalactiae' and 'neonatal'. We identified 1740 abstracts from which we retrieved 45 fulltext articles. The search was subsequently updated on 14 October 2011. In all, 538 titles or abstracts were identified, from which we retrieved 21 full-text articles. We supplemented our search with review of the reference lists of relevant publications. From a final 28 full-text articles deemed appropriate for our study population and research question, along with national reports, we derived estimates of the value and plausible ranges for all probability, cost and utility data associated with each of the health events in the model (Table 1). ${ }^{12-47}$

Effectiveness was measured using quality-adjusted lifeyears (QALYs). For an individual person, QALY is computed by multiplying the number of expected life-years in each health state by the 'utility' associated with that health state and then summing across the health states. A utility score provides a quantification of an average person's preference for being in a particular health state. It is a continuous measure with values ranging from 0 to 1 , with 0 representing death and 1 representing perfect health. A health state less than perfect health but better than death would take a value between 0 and 1 . Because of the lack of estimates for the utility scores of long-term sequelae of EOGBS sepsis, we used the corresponding values for individuals with cerebral palsy as an approximation. ${ }^{42,43}$

Likewise, annual cost and life expectancy associated with individuals manifesting sequelae of EOGBS sepsis were approximated using the corresponding values for individuals 


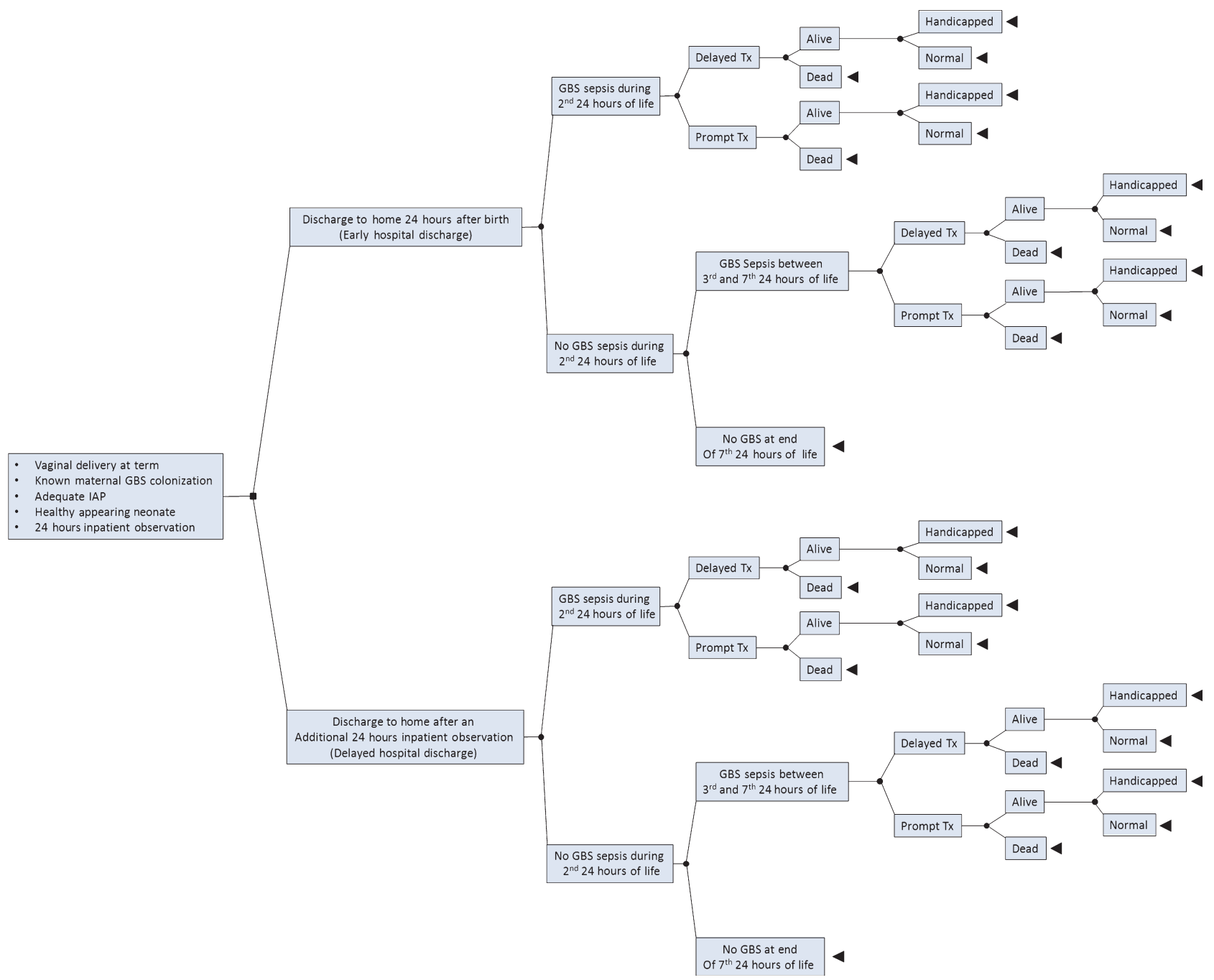

Figure 1. Decision tree model. The decision analysis begins after the first 24 hour in-hospital observation period has been completed and the newborn is asymptomatic at that time; no costs or sequelae associated with the first 24-hour inpatient observation are included in the model. Filled square indicates a decision node, filled circle indicates a chance event, and filled triangle indicates an end node of a branch. Tx = treatment.

with cerebral palsy. ${ }^{37,41}$ For individuals who never developed EOGBS sepsis or who were successfully treated for EOGBS sepsis, i.e. without long-term sequelae, we adjusted each additional surviving year of their life with the age-specific health-related quality of life for the average US population. ${ }^{47}$ This is to account for the fact that people could suffer from other diseases throughout their lifespan and hence have less than perfect health in subsequent life years. Data sources used for probability and cost estimates were assessed for their level of evidence by two authors (MBB and ELM) (Table 1). The sources were independently assessed by the two authors using the Oxford Centre for Evidence-based Medicine-Levels of Evidence (March 2009) and consensus on a final score was determined through discussion.
We conducted the analysis from a societal perspective. All cost estimates were adjusted to 2010 US dollars. ${ }^{48}$ Cost and QALY estimates later in life were discounted to the time at birth using a $3 \%$ discount rate with sensitivity analyses conducted using a $0 \%$ and $5 \%$ discount rate, respectively.

\section{Data analysis}

As recommended by the Panel on Cost Effectiveness in Health and Medicine, we performed a multivariate sensitivity analysis using Monte Carlo simulation. ${ }^{49}$ In Monte Carlo simulation, possible values of each input parameter in the model were defined by a prespecified distribution. During each iteration of the simulation, a random value of each input parameter was drawn from such prespecified distributions, which forms one set of parameter values. The 
Table 1. Parameter estimates for the model

\begin{tabular}{|c|c|c|c|c|c|}
\hline Parameter & $\begin{array}{l}\text { Most } \\
\text { likely value }\end{array}$ & Minimum & Maximum & Reference & $\begin{array}{l}\text { Level of } \\
\text { evidence }\end{array}$ \\
\hline $\begin{array}{l}\text { Among term neonates born to women known to be colonised by GBS } \\
\text { but who received adequate IAP, the probability that EOGBS sepsis } \\
\text { develops during the first } 24 \text { hours* }\end{array}$ & $0.0396 \%$ & $0.0210 \%$ & $0.0450 \%$ & $12-16$ & $\begin{array}{l}2 b, 2 b, 2 b \\
5,2 b\end{array}$ \\
\hline $\begin{array}{l}\text { Among all newborns with EOGBS sepsis, the proportion that develop } \\
\text { symptoms during the first } 24 \text { hours of life* }\end{array}$ & $89.0 \%$ & $61.0 \%$ & $95.0 \%$ & $17-24$ & $\begin{array}{l}2 b, 2 b, 2 b, 1 a \\
4,1 a, 1 a, 2 b\end{array}$ \\
\hline $\begin{array}{l}\text { Among all newborns with EOGBS sepsis, the proportion that develop } \\
\text { symptoms during the second } 24 \text { hours* }\end{array}$ & $5.0 \%$ & $3.0 \%$ & $32 \%$ & $\begin{array}{l}17,20,22 \\
25,26\end{array}$ & $\begin{array}{l}2 b, 1 a, 1 a \\
4,2 c\end{array}$ \\
\hline $\begin{array}{l}\text { Probability of delayed treatment for newborns that develop EOGBS } \\
\text { sepsis while under hospital observation }\end{array}$ & $1.0 \%$ & $0.0 \%$ & $5.0 \%$ & 18 & $2 b$ \\
\hline $\begin{array}{l}\text { Probability of delayed treatment for newborns that develop EOGBS } \\
\text { sepsis while not under hospital observation }\end{array}$ & $100 \%$ & - & - & $\begin{array}{l}\text { Authors' } \\
\text { assumption }\end{array}$ & 5 \\
\hline $\begin{array}{l}\text { Probability of death among newborns with EOGBS sepsis and delayed } \\
\text { treatment }\end{array}$ & $10.0 \%$ & $8.0 \%$ & $12.0 \%$ & $27-29$ & $2 b, 5,5$ \\
\hline $\begin{array}{l}\text { Probability of having long-term sequelae among newborns with EOGBS } \\
\text { sepsis and delayed treatment }\end{array}$ & $30.0 \%$ & $20.0 \%$ & $40.0 \%$ & 27 & $2 b$ \\
\hline $\begin{array}{l}\text { Probability of death among newborns with EOGBS sepsis and prompt } \\
\text { treatment }\end{array}$ & $3.0 \%$ & $1.0 \%$ & $5.0 \%$ & $27-30$ & $2 b, 5,5,2 b$ \\
\hline $\begin{array}{l}\text { Probability of having long-term sequelae among newborns with EOGBS } \\
\text { sepsis and prompt treatment }\end{array}$ & $14.0 \%$ & $2.0 \%$ & $26.0 \%$ & $27,28,30$ & $2 b, 5,2 b$ \\
\hline Cost of an additional 24-hour hospital observation & $\$ 1,182$ & $\$ 591$ & $\$ 1,773$ & 31,32 & $2 b, 2 c$ \\
\hline $\begin{array}{l}\text { Cost of an emergency department visit for newborns developing } \\
\text { EOGBS sepsis while not under inpatient observation }\end{array}$ & $\$ 341$ & $\$ 171$ & $\$ 512$ & 33,34 & $2 c, 2 c$ \\
\hline Cost of EOGBS sepsis treatment & $\$ 23,021$ & $\$ 17,662$ & $\$ 95,102$ & $31,34-36$ & $2 b, 2 c, 2 c, 1 b$ \\
\hline Lifetime cost of long-term sequelae resulting from EOGBS sepsis** & $\$ 1,018,465$ & $\$ 509,232$ & $\$ 1,527,697$ & 37 & $2 c$ \\
\hline Usual weekly earnings of US workers*** & $\$ 747$ & $\$ 290$ & $\$ 1,769$ & 38 & $2 c$ \\
\hline $\begin{array}{l}\text { Life expectancy at birth for newborns without EOGBS sepsis or with } \\
\text { successfully treated EOGBS sepsis }\end{array}$ & 77.90 & - & - & 40 & $2 c$ \\
\hline $\begin{array}{l}\text { Life expectancy at birth for newborns with long-term sequelae } \\
\text { resulting from EOGBS sepsis** }\end{array}$ & 42.70 & 11.20 & 67.70 & 41 & 2c \\
\hline $\begin{array}{l}\text { Utility weight of health state with long-term sequelae resulting from } \\
\text { EOGBS sepsis** }\end{array}$ & 0.40 & 0.13 & 0.56 & 42,43 & $2 b, 2 b$ \\
\hline Utility weight of EOGBS sepsis health state ${ }^{* * *}$ & 0.92 & 0.66 & 0.93 & 44,47 & $2 c$ \\
\hline Duration of EOGBS sepsis symptoms (days) & 8.80 & 0.00 & 34.20 & 45,46 & $2 b, 2 b$ \\
\hline Age-specific utility weights for the average US population & & & & 47 & $2 c$ \\
\hline $0-5$ & 0.94 & - & - & & \\
\hline $5-15$ & 0.93 & - & - & & \\
\hline $15-20$ & 0.92 & - & - & & \\
\hline $20-30$ & 0.91 & - & - & & \\
\hline $30-35$ & 0.90 & - & - & & \\
\hline $35-40$ & 0.89 & - & - & & \\
\hline $40-45$ & 0.88 & - & - & & \\
\hline $45-50$ & 0.86 & - & - & & \\
\hline $50-55$ & 0.83 & - & - & & \\
\hline $55-60$ & 0.81 & - & - & & \\
\hline $60-65$ & 0.77 & - & - & & \\
\hline $65-70$ & 0.76 & - & - & & \\
\hline $70-75$ & 0.74 & - & - & & \\
\hline $75-80$ & 0.70 & - & - & & \\
\hline
\end{tabular}

EOGBS, early-onset group B streptococci; GBS, group B streptococci; IAP, intrapartum antibiotic prophylaxis.

All cost estimates reflect inflation against 2010 US dollars.

*These parameters were used to derive the probability of developing EOGBS sepsis during the second 24 hours of life (conditional on surviving the first 24 hours without EOGBS sepsis) and the probability of developing EOGBS sepsis after 48 hours of birth but within 7 days of birth (conditional on surviving the first 48 hours of life without EOGBS sepsis).

${ }^{* *}$ Approximated using data from individuals with cerebral palsy.

$* * *$ This reflects the 90 th centile of usual weekly earnings and was accounted for as such in the simulation.

$* * * *$ Approximated using the utility of need for admission to neonatal nursery. 
model is then run for this simulated parameter set and the outcome measures are therefore calculated. This process is repeated many times to account for the uncertainty of parameter values. In our analysis, we performed Monte Carlo simulation with 5000 iterations.

For each of the probability, utility and cost parameters in our model, we assumed a PERT (Program Evaluation and Review Technique) distribution, which is a special form of the beta distribution and specifies minimum, maximum and most likely values as its distribution parameters (Table 1). ${ }^{50}$ With 5000 iterations of data, the mean and 95\% confidence intervals (95\% CIs) for the expected cost and QALY associated with early and delayed hospital discharge, respectively, were calculated. Because our model starts at 24 hours after birth with an asymptomatic newborn, the estimated cost and QALY reflect the values starting from the second 24 hours of life throughout the lifetime of the newborn. We also estimated the mean and 95\% CIs for the expected incremental cost, incremental QALY, and the incremental cost-effectiveness ratio (ICER), i.e. incremental cost divided by incremental QALY. A costeffectiveness plane and cost-effectiveness acceptability curve were also constructed to assess the probability distribution of the ICER.

Because estimates of cost, QALY, ICER and probability of adverse outcomes are not normally distributed in our simulation data, we estimated their $95 \%$ CIs based on a non-parametric method using the 2.5th and 97.5th centiles. ${ }^{51}$ Debate is ongoing regarding whether to include productivity cost in the numerator of the ICER, ${ }^{52-55}$ so we included costs associated with productivity loss in primary analysis, but performed a sensitivity analysis excluding such costs. DecisionTools Suite ${ }^{\circledR}$ software (Palisade Corporation, Ithaca, NY, USA) and SAS 9.2 (SAS Institute Inc., Cary, NC, USA) were used for data analysis.

\section{Results}

Our analysis suggests that an additional 24-hour inpatient observation results in slightly higher expected QALY as compared with discharge at 24 hours of life (27.72054 versus 27.72038) (Table 2). This is because the longer inhospital observation increases the likelihood of providing prompt treatment for EOGBS sepsis, hence reducing the probability of neonatal death and adverse long-term health sequelae. However, the mean expected cost of delayed discharge, i.e. $\$ 1198.93$, is approximately 43 -fold higher than that of early hospital discharge, i.e. \$27.98. To assess whether the expected QALYs differ significantly between the two discharge strategies, we draw on the estimated 95\% CIs of the expected difference in QALY (and likewise for expected cost). This is because within each iteration of the simulation, the estimated QALYs for the two discharge strategies were based on the same set of parameter values drawn and hence, were not independent from each other (and, likewise, for the estimated costs associated with the two discharge strategies). The 95\% CI for the expected difference in cost and QALY suggest that both were statistically significant. However, delayed hospital discharge, in an attempt to improve neonatal outcomes, is associated with substantial additional costs (\$1170.96 with 95\% CI \$750.13-1584.32) while resulting in minimal QALY gain $(0.00016$ with $95 \%$ CI $0.00005-$ 0.00040). The mean ICER, or the additional cost to society to gain one extra QALY, is $\$ 9,771,520.87$ (95\% CI: $\$ 2,573,139.89$ to $\$ 24,407,017.82$ ).

Our model also suggests that delayed hospital discharge has minimal effects not only on the expected QALYs but on clinically relevant health outcomes as well. For example, with delayed hospital discharge, the expected probability that the newborn would die from EOGBS sepsis is $0.00043 \%$. By contrast, the expected probability that the newborn would die from EOGBS sepsis following early hospital discharge is $0.00066 \%$, with the expected difference being $0.00023 \%$ (95\% CI $0.00008-0.00054 \%$ ) between the two strategies. Likewise, the probability that the newborn would have long-term health sequelae is $0.00146 \%$ and $0.00198 \%$, respectively, following delayed and early hospital discharge, with the difference being $0.00052 \%$ (95\% CI $0.00011-0.00141 \%)$.

Table 2. Summary of simulation results

Delayed hospital discharge

$\$ 1198.93(\$ 776.25-1614.38)$

Expected cost (US\$)

Expected QALY

Expected difference in cost

Expected difference in QALY

Incremental cost-effectiveness ratio
27.72054 (27.71991-27.72083)

$\$ 1170.96(\$ 750.13-1584.32)$

$0.00016(0.00005-0.00040)$

$\$ 9,771,520.87(\$ 2,573,139.89-24,407,017.82)$
Early hospital discharge

$\$ 27.98(\$ 8.94-64.75)$

$27.72038(27.71969-27.72074)$

Data are reported as mean (95\% confidence interval). The expected cost and QALYs reflect the values starting from the second 24 hours of life throughout the lifetime of the newborn. 


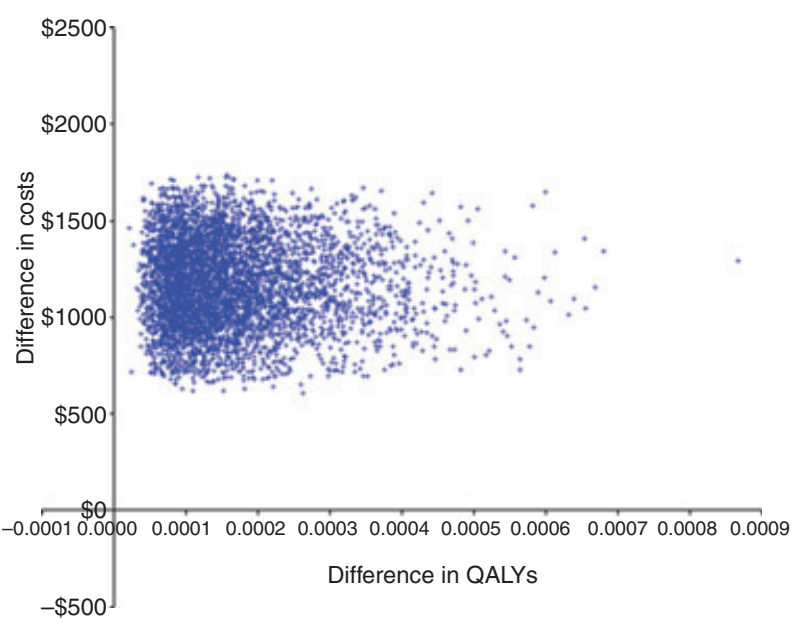

Figure 2. A cost-effectiveness plane was generated based on data from the 5000 iterations of the Monte Carlo simulation. The horizontal axis represents the difference in QALYs between delayed and early hospital discharge. The vertical axis represents the difference in costs between delayed and early hospital discharge. Each dot on the plane corresponds to the values resulting from one iteration of the Monte Carlo simulation.

The results of 5000 iterations of our simulation analysis are shown in a cost-effectiveness plane (Figure 2). This figure plots the joint distribution of the incremental cost and incremental QALY when comparing discharge after an additional 24 hours of in-hospital observation with discharge at 24 hours after birth. Each dot on the plane corresponds to one incremental cost and QALY pair resulting from one iteration of the simulation. All 5000 incremental cost and QALY pairs fall within the northeast quadrant of the cost-effectiveness plane, indicating a trade-off between the cost and the QALY. That is, delayed hospital discharge results in higher QALYs than early hospital discharge, but is also more costly than early hospital discharge. Figure 2 illustrates significant variability in the magnitude of the ICER.

To further evaluate the probability distribution of the ICER, we generated a cost-effectiveness acceptability curve (Figure 3). This curve reflects the probability that the additional 24-hour inpatient observation is cost-effective compared with early discharge at different levels of ceiling acceptable cost-effectiveness ratios. The ceiling acceptable cost-effectiveness ratio indicates the maximum amount that society would be willing to pay to gain one extra QALY. For each given ceiling acceptable cost-effectiveness ratio, we calculated the proportion of simulations in our analysis in which the expected ICER was lower than that ratio. This proportion estimates the probability that an additional 24hour inpatient observation is a more cost-effective strategy than discharge at 24 hours after birth. The minimum ICER generated in our simulation ( $n=5000$ iterations) was

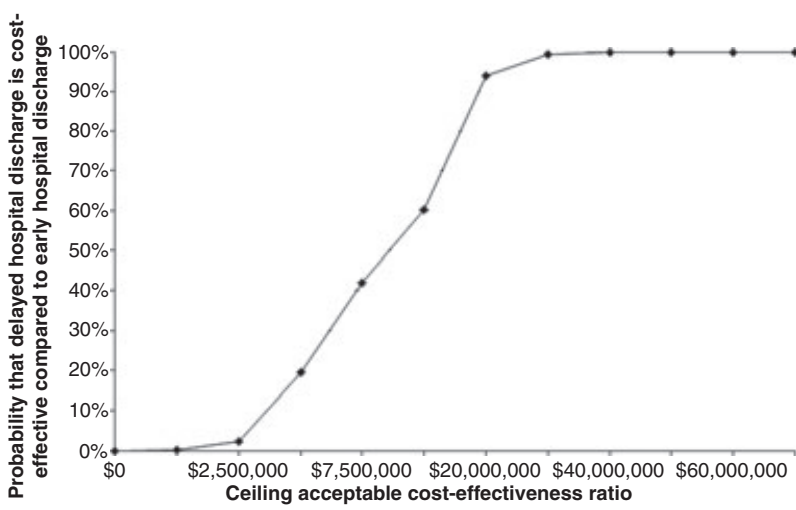

Figure 3. A cost-effectiveness acceptability curve demonstrates the probability that the additional 24-hour inpatient observation is costeffective compared with early hospital discharge based upon different levels of ceiling acceptable cost-effectiveness ratios. The ceiling acceptable cost-effectiveness ratio indicates the maximum amounts that society would be willing to pay to gain one extra QALY.

$\$ 1,294,000.93$ per QALY, which is more than 25-fold greater than the commonly used maximum acceptable cost-effectiveness ratio of $\$ 50,000$ per QALY. ${ }^{56}$ Although there has been debate regarding the appropriate dollar value per QALY gained upon which to base resource allocation decisions, the ICER estimates found in our analysis do not suggest that an additional 24 hours of inpatient observation is a cost-effective approach even when using other, more lenient, estimates of cost per QALY (e.g. $\$ 100,000 /$ QALY). ${ }^{56}$

Our simulation data suggest that the most important factors influencing the cost-effectiveness of the additional 24 hours of inpatient observation include: the proportion of EOGBS sepsis that develops during the second 24 hours of life, the cost of 24 hours of inpatient observation, and the probability of having long-term health sequelae following prompt versus delayed GBS treatment. In addition, sensitivity analyses excluding costs for lost productivity generated similar findings in terms of the overall cost-effectiveness of delayed hospital discharge (mean ICER $=\$ 9,725,642.82$; 95\% CI $\$ 2,739,790.40-23,726,212.41$; data not shown in table). Varied discount rates (0\% and 5\%) did not affect the key findings either.

\section{Discussion}

In this study, we compared the cost-effectiveness of two hospital discharge approaches for term neonates who are asymptomatic at 24 hours after birth and were born via vaginal delivery to women colonised by GBS but treated with adequate IAP: discharge at 24 hours after birth versus discharge after an additional 24-hour inpatient observation. The results suggest that discharging these infants after an additional 24-hour inpatient observation is not a 
cost-effective approach, resulting in an estimated ICER much higher than the conventionally accepted cost-effectiveness thresholds.

It has been well documented that approximately $90 \%$ of neonates with EOGBS sepsis develop symptoms within the first 24 hours of life. ${ }^{17,18,21,22,24}$ In addition, it has been demonstrated that physical examination is more sensitive than various laboratory studies for identifying neonates with sepsis, ${ }^{16}$ suggesting that newborns can be effectively monitored at home. It is therefore interesting that the recently revised CDC guidelines still recommend 48 hours of inpatient observation for 'well-appearing infants...whose mother received adequate intrapartum GBS prophylaxis'. ${ }^{6}$ It should be noted that these updated guidelines continue to indicate that 24 hours of in-hospital observation may be sufficient, provided that ready access to medical care is available and a person will be present who can comply with instructions for home observation.

The CDC guidelines for GBS screening and prophylaxis have resulted in remarkable improvements in the rates of EOGBS sepsis, but have not strongly addressed their impact on healthcare costs. In fact, the newest revision of the guidelines highlights the need for further studies of the effect of the guidelines on healthcare resource utilisation and their influence on neonatal management strategies. ${ }^{6}$ Therefore, our study is an important addition to the current literature on EOGBS sepsis as the existing GBS costeffectiveness studies have focused on the costs and benefits of screening and treatment, ${ }^{30,31,57}$ rather than discharge strategies after the baby is born.

Cost-effectiveness analyses, such as the one presented in this study, have a marked potential to affect healthcare policy. The costs, risks and benefits of any strategy must therefore be considered in the context of existing legislation governing related practices. The Newborns' and Mothers' Health Protection Act of 1996 (and, similarly, statutes enacted by a majority of states in the USA) states that the hospital stay after a vaginal delivery cannot be restricted to less than 48 hours. This law does not, however, mandate that women must stay in the hospital for 2 days postpartum; rather, it is designated to regulate the minimum benefits covered by health-insurance providers. Indeed, a recent Policy Statement from the AAP's Committee on Fetus and Newborn explicitly acknowledges that discharge $<48$ hours after delivery may be appropriate. ${ }^{58}$

These results must also be interpreted in the context of prior experience with early hospital discharge of neonates. In both private pay and Medicaid populations, large timeseries analyses of the effects of passage of length-of-stay laws have been shown to result in similar health outcomes, with similar rates of re-hospitalisation for all causes. ${ }^{59-61} \mathrm{~A}$ recent Cochrane review of this subject similarly showed that although there is significant heterogeneity in studies comparing early and delayed discharge, maternal and neonatal outcomes appear to be similar under both strategies. $^{62}$

The large magnitude of the ICER estimate and its wide confidence interval found in our study are primarily the result of the relatively large difference in expected costs in conjunction with the minimal difference in health outcomes expected from the two discharge approaches. This results in large estimates of the numerator with quite small estimates of the denominator for the ICER. Variations in the denominator across the 5000 iterations of the simulation led to large changes in the ICER estimates. However, even the minimum ICER calculated by our model, i.e. $\$ 1,294,000.93$, is substantially higher than the commonly accepted cost-effectiveness threshold value of $\$ 50,000$ 100,000 per QALY. ${ }^{56,63}$

Whether to include productivity cost in the numerator of the ICER has been controversial. ${ }^{52-55}$ The Panel on Cost Effectiveness in Health and Medicine recommended in 1996 that the monetary value of lost productivity should not be included in the numerator of the ICER to avoid double counting. ${ }^{49}$ This recommendation was based on an assumption that respondents always take lost income into consideration when evaluating the impact of a health state on their quality of life. However, none of the existing health-related quality of life instruments that are used to estimate utility weights and hence, QALYs, explicitly ask about forgone income or wages. ${ }^{55} \mathrm{~A}$ recent literature review further demonstrated that without explicit instructions on consideration of income, only a minority of respondents actually include the effects of income losses in health state valuation. ${ }^{54}$ Moreover, as argued by Meltzer and Johannesson, ${ }^{64}$ the assumption that people incorporate personal financial consequences such as income losses into healthstate evaluations implies that they would also incorporate other consequences such as out-of-pocket medical expenses related to the health state, which may result in another type of double counting as medical care costs of related diseases is already included in the numerator.

Due to these considerations, we included productivity costs in our primary analysis, but ran a sensitivity analysis excluding such costs. There is no meaningful difference in our conclusion. Indeed, because hospital discharge at 24 hours of life is associated with a greater probability of neonatal death and long-term adverse health sequelae because of delayed treatment of EOGBS sepsis, disregarding productivity costs associated with premature death and lost work time for those with long-term health sequelae would change the results more in favour of early hospital discharge. As our primary analysis already suggests that early hospital discharge is the more cost-effective approach, exclusion of productivity cost should not affect this conclusion. 
The primary strength of this study is that it compares a common practice that is in place for the purpose of protecting against the long-term, devastating and potentially expensive sequelae of EOGBS sepsis with a standard that has been emerging for many other healthcare and prevention strategies. ${ }^{65}$ By attempting to frame this intervention in this capacity, society can compare the cost-effectiveness across different healthcare interventions to optimise allocation of our resources.

Fargason et al. ${ }^{57}$ have performed an analysis of paediatric costs associated with the management of infants born to GBS-positive mothers who received adequate intrapartum prophylaxis after either a risk-based or culture-based approach. Their study found that costs of paediatric care constituted a large fraction of the cost per sepsis case averted, although the degree to which paediatric observation may prevent or attenuate EOGBS disease is not established. The authors note that in their cost analysis, the length of neonatal observation significantly influences the cost of sepsis prevention; however they did not explicitly compare early versus delayed hospital discharge. ${ }^{57}$ In the current study, we demonstrate that compared with early discharge, delayed hospital discharge of healthy-appearing term neonates born to colonised mothers who receive adequate IAP is not cost-effective. Given that approximately $10-30 \%$ of all pregnant women in the USA have been shown to be colonised with GBS, ${ }^{7}$ guidelines surrounding the appropriate length of inpatient observation for neonates born to women known to be colonised by GBS but with adequate IAP have substantial cost implications.

Several limitations of the study should be acknowledged. First, all modelling studies require simplification, and several assumptions must be made because of lack of data. For example, we assumed that under the early hospital discharge strategy, all neonates with EOGBS sepsis symptoms developed after the first 24 hours would receive delayed treatment. This may be an oversimplification of real life when some neonates may still be able to get prompt treatment. However, relaxing this assumption should not change our conclusion as more lenient assumptions would further strengthen the case in favour of the early discharge strategy. Second, there is a lack of data on the utility and medical cost of individuals with long-term sequelae following EOGBS sepsis. Hence, we used the estimates for persons with cerebral palsy as an approximation. Third, the estimates for the cost, utility and probability parameters in our model are based on published literature. No primary data collection was performed for this study; therefore some parameter estimates may have a relatively wide range. However, we conducted substantial sensitivity analysis to assure the robustness of our findings. Finally, our parameters on treatment pattern and incidence of health sequelae were based on best data available in published literature up to October 2011; these estimates might change in the future as more accurate diagnostic tools and more effective treatments become available.

\section{Conclusion}

Intrapartum antibiotic prophylaxis of GBS-colonised mothers has greatly reduced the incidence of early onset GBS sepsis in the USA and elsewhere. Our cost-effectiveness analysis suggests that in the setting of having provided adequate IAP, discharging healthy-appearing term neonates born to GBS-colonised mothers after 24 hours is the preferred approach compared with 48 hours of inpatient observation. Our findings, along with other data in the literature, also suggest that safety and cost-effectiveness depend on timely identification and treatment of GBS disease in the neonate. Future research focusing on tools for early identification of neonates at risk for developing GBS sepsis before the development of symptoms will be useful.

\section{Disclosure of interests}

The authors have no financial relationships relevant to this article to disclose.

\section{Contribution to authorship}

MBB developed the core study idea, and participated in the literature review, analysis of the results and drafted the paper. XX participated in the study design, performed the data analysis and participated in drafting the paper. JAW participated in developing the study design, literature review and drafting the paper. CJMV participated in developing the study design and editing the paper. ELM participated in the study design, literature review, analysis of results and drafting the paper.

\section{Details of ethics approval}

Institutional Review Board approval was not necessary for this study because no patient information was used.

\section{Funding}

No funding was required for completion of this study.

\section{Acknowledgements}

Preliminary results from this study were presented at the American College of Obstetricians and Gynecologists 56th Annual Clinical Meeting on 5 May 2008 as an oral abstract.

\section{References}

1 Department of Health and Human Services. Prevention of perinatal group B streptococcal disease: a public health perspective. Centers for Disease Control and Prevention. MMWR Recomm Rep 1996;45:1-24. 
2 Department of Health and Human Services. Early-onset and late-onset neonatal group B streptococcal disease-United States, 1996-2004. MMWR Morb Mortal Wkly Rep 2005;54:1205-8.

3 Gotoff SP. Group B streptococcal infections. Pediatr Rev 2002; 23:381-6.

4 Mullaney DM. Group B streptococcal infections in newborns. J Obstet Gynecol Neonatal Nurs 2001;30:649-58.

5 Ohlsson A, Shah VS. Intrapartum antibiotics for known maternal Group B streptococcal colonization. Cochrane Database Syst Rev 2009;3:CD007467.

6 Verani JR, McGee L, Schrag SJ. Prevention of perinatal group B streptococcal disease-revised guidelines from CDC, 2010. MMWR Recomm Rep 2010;59:1-36.

7 Schrag S, Gorwitz R, Fultz-Butts K, Schuchat A. Prevention of perinatal group B streptococcal disease. Revised guidelines from CDC. MMWR Recomm Rep 2002;51:1-22.

8 Schrag SJ, Whitney CG, Schuchat A. Neonatal group B streptococcal disease: how infection control teams can contribute to prevention efforts. Infect Control Hosp Epidemiol 2000;21:473-83.

9 Tumbaga PF, Philip AGS. Perinatal Group B Streptococcal Infections and the new guidelines: an update. Neoreviews 2006;7:e52430.

10 Baker CJ. CDC revises group B strep prevention guidelines. AAP News 2002;21:118.

11 Glasgow TS, Speakman M, Firth S, James B, Byington CL, Young PC. Clinical and economic outcomes for term infants associated with increasing administration of antibiotics to their mothers. Paediatr Perinat Epidemiol 2007;21:338-46.

12 Renner RM, Renner A, Schmid S, Hoesli I, Nars P, Holzgreve W, et al. Efficacy of a strategy to prevent neonatal early-onset group $B$ streptococcal (GBS) sepsis. J Perinat Med 2006;34:32-8.

13 Velaphi S, Siegel JD, Wendel GD Jr, Cushion N, Eid WM, Sanchez PJ. Early-onset group B streptococcal infection after a combined maternal and neonatal group B streptococcal chemoprophylaxis strategy. Pediatrics 2003;111:541-7.

14 Baltimore RS, Huie SM, Meek JI, Schuchat A, O'Brien KL. Early-onset neonatal sepsis in the era of group B streptococcal prevention. Pediatrics 2001;108:1094-8.

15 Apgar BS, Greenberg G, Yen G. Prevention of group B streptococcal disease in the newborn. Am Fam Physician 2005;71:903-10.

16 Escobar GJ, Li DK, Armstrong MA, Gardner MN, Folck BF, Verdi JE, et al. Neonatal sepsis workups in infants $>/=2000$ grams at birth: a population-based study. Pediatrics 2000;106:256-63.

17 Trijbels-Smeulders M, Gerards L, Pasker-de Jong PCM, de Jong P, van Lingen RA, Adriaanse AH, et al. Epidemiology of neonatal group B streptococcal disease in The Netherlands 1997-98. Paediatr Perinat Epidemiol 2002;16:334-41.

18 Bromberger P, Lawrence JM, Braun D, Saunders B, Contreras R, Petitti DB. The influence of intrapartum antibiotics on the clinical spectrum of early-onset group B streptococcal infection in term infants. Pediatrics 2000;106:244-50.

19 Chen KT, Ringer S, Cohen AP, Lieberman E. The role of intrapartum fever in identifying asymptomatic term neonates with early-onset neonatal sepsis. J Perinatol 2002;22:653-7.

20 Zaleznik DF, Rench MA, Hillier S, Krohn MA, Platt R, Lee ML, et al. Invasive disease due to group B Streptococcus in pregnant women and neonates from diverse population groups. Clin Infect Dis 2000;30:276-81.

21 Heath PT, Balfour GF, Tighe H, Verlander NQ, Lamagni TL, Efstratiou A, et al. Group B streptococcal disease in infants: a case control study. Arch Dis Child 2009;94:674-80.

22 Berardi A, Lugli L, Baronciani D, Rossi C, Ciccia M, Creti R, et al. Group B Streptococcus early-onset disease in Emilia-romagna: review after introduction of a screening-based approach. Pediatri Infect Dis J 2010;29:115-21.

23 Schrag SJ, Zywicki S, Farley MM, Reingold AL, Harrison LH, Lefkowitz LB, et al. Group B streptococcal disease in the era of intrapartum antibiotic prophylaxis. N Engl J Med 2000;342:15-20.

24 Mifsud AJ, Efstratiou A, Charlett A, McCartney AC. Early-onset neonatal group B streptococcal infection in London: 1990-1999. BJOG 2004;111:1006-11.

25 Oddie S, Embleton ND. Risk factors for early onset neonatal group B streptococcal sepsis: case-control study. BMJ 2002;325:308.

26 Schuchat A, Zywicki SS, Dinsmoor MJ, Mercer B, Romaguera J, O'Sullivan MJ, et al. Risk factors and opportunities for prevention of early-onset neonatal sepsis: a multicenter case-control study. Pediatrics 2000;105:21-6.

27 Fluegge K, Siedler A, Heinrich B, Schulte-Moenting J, Moennig MJ, Bartels $D B$, et al. Incidence and clinical presentation of invasive neonatal group B streptococcal infections in Germany. Pediatrics 2006;117:e1139-45.

28 Gibbs RS, Schrag S, Schuchat A. Perinatal infections due to group B streptococci. Obstet Gynecol 2004;104:1062-76.

29 Remington JS, Klein JO. Infectious diseases of the fetus and newborn infant. Philadelphia: Saunders, 2001.

30 Akker-van Marle ME, Rijnders ME, Dommelen P, Fekkes M, Wouwe $J P$, Amelink-Verburg MP, et al. Cost-effectiveness of different treatment strategies with intrapartum antibiotic prophylaxis to prevent early-onset group B streptococcal disease. BJOG 2005;112:820-6.

31 Mohle-Boetani JC, Lieu TA, Ray GT, Escobar G. Preventing neonatal group B streptococcal disease: cost-effectiveness in a health maintenance organization and the impact of delayed hospital discharge for newborns who received intrapartum antibiotics. Pediatrics 1999;103: 703-10.

32 Evans WN, Garthwaite C, Wei H. The impact of early discharge laws on the health of newborns. J Health Econ 2008;27:843-70.

33 Hospital Outpatient PPS [www.cms.gov/HospitalOutpatientPPS]. Accessed 30 September 2011.

34 Physician Fee Schedule. [www.cms.gov/PhysicianFeeSched]. Accessed 30 September 2011.

35 Acute Inpatient PPS - FY2010 Final Rule Home Page. [www.cms.gov/ AcutelnpatientPPS/10FR/list.asp\#TopOfPage]. Accessed 30 September 2011.

36 Turrentine MA, Ramirez MM, Mastrobattista JM. Cost-effectiveness of universal prophylaxis in pregnancy with prior group B streptococci colonization. Infect Dis Obstet Gynecol 2009;2009:934698.

37 Honeycutt AA, Grosse SD, Dunlap LJ, Schendel DE, Chen H, Brann $E$, et al. Economic costs of mental retardation, cerebral palsy, hearing loss, and vision impairment. In: Altman BM, Barnartt SN, Henderschot G, Larson S, editors. Using Survey Data to Study Disability: Results from the National Health Interview Survey on Disability. London: Elsevier Science, Ltd.; 2003. pp. 207-28.

38 Highlight of Women's Earnings in 2010. July 2011. Report 1031. [www.bls.gov/cps/cpswom2010.pdf]. Accessed 5 October 2011.

39 Arias E. United States life tables, 2004. Nat/ Vital Stat Rep 2007;56:139.

40 Xu J, Kochanek KD, Murphy SL, Tejada-Vera B. Deaths: final data for 2007. In: U.S. Department of Health and Human Services CfDCaP, National Center for Health Statistics, National Vital Statistics System, editor. National Vital Statistics Report. Washington D.C.: U.S. Department of Health and Human Services; 2010. pp. 1-136.

41 Katz RT. Life expectancy for children with cerebral palsy and mental retardation: implications for life care planning. NeuroRehabilitation 2003;18:261-70.

42 Carroll $A E$, Downs SM. Comprehensive cost-utility analysis of newborn screening strategies. Pediatrics 2006;117:S287-95. 
43 de Lissovoy G, Matza LS, Green H, Werner M, Edgar T. Cost-effectiveness of intrathecal baclofen therapy for the treatment of severe spasticity associated with cerebral palsy. J Child Neurol 2007;22:4959.

44 Pham CT, Crowther CA. Birth outcomes: utility values that postnatal women, midwives and medical staff express. BJOG 2003;110:1217.

45 Platt R, Adelson-Mitty J, Weissman L, Zaleznik D, Lee ML, Baker CJ. Resource utilization associated with initial hospital stays complicated by early onset group B streptococcal disease. Pediatr Infect Dis J 1999;18:529-33.

46 Mayor-Lynn K, Gonzalez-Quintero VH, O'Sullivan MJ, Hartstein Al, Roger S, Tamayo M. Comparison of early-onset neonatal sepsis caused by Escherichia coli and group B Streptococcus. Am J Obstet Gynecol 2005;192:1437-9.

47 Erickson P, Wilson R, Shannon I. Years of healthy life. Healthy People 2000 Stat Notes 1995;7:1-15.

48 Consumer Price Index - CPI (All Urban Consumers). [www.bls.gov/ cpi]. Accessed 26 September 2011.

49 Weinstein MC, Siegel JE, Gold MR, Kamlet MS, Russell LB. Recommendations of the Panel on Cost-effectiveness in Health and Medicine. JAMA 1996;276:1253-8.

50 Palisade Corporation. Guide to using @RISK: Risk Analysis and Simulation Add-in for Microsoft Excel. Ithaca, NY: Palisade Corporation, 2008.

51 Lord J, Asante MA. Estimating uncertainty ranges for costs by the bootstrap procedure combined with probabilistic sensitivity analysis. Health Econ 1999;8:323-33.

52 Brouwer WB, Koopmanschap MA, Rutten FF Productivity costs in cost-effectiveness analysis: numerator or denominator: a further discussion. Health Econ. 1997;6:511-4.

53 Rothermich EA, Pathak DS. Productivity-cost controversies in costeffectiveness analysis: review and research agenda. Clin Ther $1999 ; 21: 255-67$
54 Tilling C, Krol M, Tsuchiya A, Brazier J, Brouwer W. In or out? Income losses in health state valuations: a review Value Health 2010;13:298-305.

55 Nyman JA. Productivity Costs Revisited: Toward a New Us Policy. Health Econ. 2011; DOI: 10.1002/hec.1795. [Epub ahead of print].

56 Hirth RA, Chernew ME, Miller E, Fendrick AM, Weissert WG. Willingness to pay for a quality-adjusted life year: in search of a standard. Med Decis Making 2000;20:332-42.

57 Fargason CA Jr, Peralta-Carcelen M, Rouse DJ, Cutter GR, Goldenberg RL. The pediatric costs of strategies for minimizing the risk of early-onset group B streptococcal disease. Obstet Gynecol 1997;90:347-52

58 Committee on Fetus and newborn. Hospital stay for healthy term newborns. Pediatrics 2010;125:405-9.

59 Madden JM. Effects of a law against early postpartum discharge on newborn follow-up, adverse events, and $\mathrm{HMO}$ expenditures. $N$ Engl J Med 2002;347:2031-8.

60 Meara E, Kotagal UR, Atherton HD, Lieu TA. Impact of early newborn discharge legislation and early follow-up visits on infant outcomes in a state Medicaid population. Pediatrics 2004;113:1619-27.

61 Madden JM, Soumerai SB, Lieu TA, Mandl KD, Zhang F, RossDegnan D. Length-of-stay policies and ascertainment of postdischarge problems in newborns. Pediatrics 2004;113:42-9.

62 Brown S, Small R, Argus B, Davis PG, Krastev A Early postnatal discharge from hospital for healthy mothers and term infants. Cochrane Database Syst Rev 2009;2:CD002958.

63 Chernew ME, Hirth RA, Cutler DM. Increased spending on health care: how much can the United States afford? Health Aff (Millwood) 2003:22:15-25.

64 Meltzer D, Johannesson M. Inconsistencies in the "societal perspective" on costs of the Panel on Cost-Effectiveness in Health and Medicine. Med Decis Making 1999;19:371-7.

65 Sculpher M. The use of quality-adjusted life-years in cost-effectiveness studies. Allergy 2006;61:527-30. 